\title{
The Assessment of Hatch Window, Hatchability and Quality of Broiler Chicks Obtained from Different Breeder Strains in a Commercial Hatchery
}

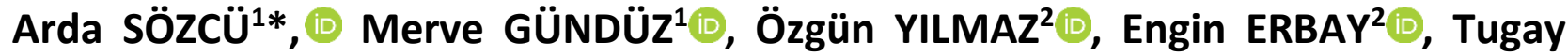 \\ CENGIZ $^{2}$, Bircan ÖZKAN ${ }^{2}$, Aydın IPEK ${ }^{1} \mathbb{D}$
}

${ }^{1}$ Bursa Uludağ University, Faculty of Agriculture, Department of Animal Science, Bursa, Turkey

${ }^{2}$ HasTavuk Food, Agriculture Livestock Industry and Trade Inc., Bursa, Turkey

\section{Article History}

Received 04 Aug 2021

Accepted 31 Dec 2021

First Online (Early view webde

yayınlanma tarihi)

\section{Corresponding Author \\ Tel.: +902242941461 \\ E-mail: ardasozcu@uludag.edu.tr}

\section{Keywords \\ Broiler chicks \\ Hatch window \\ Eggshell temperature \\ Chick quality}

\begin{abstract}
The objective of this study was to assess the hatch window, hatchability and quality of broilers' chick obtained from different breeder strains in a commercial hatchery. A total of 57600 hatching eggs ( 28800 hatching eggs per strain) were collected from commercial flocks of Cobb 500 and Ross 308 broiler breeder parent stocks at 60-61 weeks of age. Each strain was randomly coded as A strain and B strain. The mean value of eggshell temperature was found to be higher in eggs obtained from Strain A (101.05 $\left.{ }^{\circ} \mathrm{F}\right)$ than the other eggs of Strain $B\left(100.98^{\circ} \mathrm{F}, \mathrm{P}<0.01\right)$. The percentage of hatched chicks at $486 \mathrm{~h}$ of incubation period was found to be as $82.1 \%$ and $62.6 \%$ of Strain $A$ and Strain B eggs respectively, whereas $84.9 \%$ and $67.7 \%$ of Strain A and Strain B eggs at $498 \mathrm{~h}$ of incubation period $(P<0.01)$. The relative chick weight was found to be higher in the chicks obtained from Strain B (67.5\%), compared to the Strain A (65.9\%; $P<0.01)$. These findings could be instructive for commercial hatcheries about the requirements of the hatching eggs obtained from different breeder strains at particular age and contribute the optimization of eggs' management and processing.
\end{abstract}

\section{Introduction}

Turkey is one of the biggest broiler meat producers throughout the world and is ranked at the $10^{\text {th }}$ place in the world broiler producer countries list supplying 2.07 million tonnes in 2020 (Besd-Bir, 2021). Therefore, the broiler production has crucial importance both home consumption and exportation for supplying the animal protein sources for human nutrition.

In broiler production, profitable producing is largely dependent on obtaining good quality and healthy hatching eggs with a successful broiler breeder production process. The chick quality is an important factor, especially for broiler breeder producers who is paid according to the number of saleable high quality one day old chicks and, also broiler producers due to high growing performance of these chicks. It is known that the chick quality is a complex issue affected by many factors including breeder strain, age, egg size (Nangsuay et al., 2016, 2017), eggshell temperature (Ipek and Sozcu, 2015; Sozcu and Ipek, 2015); hatch window (Sozcu et al, 2018) and hatching time (Romanini et al., 2013).

Recent studies reported that poor incubation conditions could result in insufficient embryo development, lower hatchability, and poorer chick quality at hatch (Lourens, 2003; Willemsen et al., 2008; Ipek et al., 2014; Sozcu and Ipek, 2015). 
Due to sensitivity of modern broiler embryos against temperature fluctuations, maintaining of the incubator temperature between optimum ranges has crucial importance to obtain better results in commercial hatcheries. Moreover, the embryo temperature is often accepted as a tool or an important indicator of the proper temperature pattern of the egg incubation process (Lourens, 2008). On the other hand, undesirable fluctuations in the setter or hatcher temperatures could cause major economic losses due to detrimental effects on hatchability, chick quality and subsequently broiler growing performance (Molenaar et al., 2010).

Especially in large scale hatcheries, some problems with temperature degrees in setter or hatcher could cause an overheating or cooling some eggs in incubator, especially during late term of incubation period (Romanini et al., 2013). Therefore, the embryo development rate could show some changes between the eggs in the incubator in the view of embryonic development rate and hatching process. Hatch window could be described as time difference between the first and the last hatched chicks during hatching period (Romanini et al., 2013). In commercial hatcheries, the total duration of incubation period could last approximately 504-510 hours, and in some cases, it could be prolonged more than 510 hours in large scale hatcheries under commercial conditions (Vieira and Pophal, 2000; Almeida et al., 2008). Accordingly, the time interval between the first and last hatched chicks could increase, and the early hatched chicks remain without food and water for the time from hatching to the time of placing broiler house (Noy and Sklan, 1997; Dibner et al., 1998; Careghi et al., 2005). After hatching, a delay in feed access negatively affects yolk utilization, small intestinal development, and growth rate during broiler growing period (Careghi et al., 2005; Mahmoud and Edens, 2012). Recent studies showed that the hatch window affected the chick quality at hatch and subsequently broiler performance during post-hatch period (Sozcu et al., 2018, 2020). In broiler production, definition of the day-old chick quality with higher accuracy is an important factor for the prediction of broiler growth performance, especially because it is known that there is relation between chick quality and first-week chick mortalities due to omphalitis and growth rate.

In large scale production, it is crucial to know the requirements of hatching eggs during incubation according to the breeder strain, age, storage condition and duration, to obtain successful results and higher profit. Because all these factors have significant impacts on embryo development, chick quality and post-hatch growing performance in broiler production. The optimizing of incubation conditions could be difficult in some cases in commercial hatcheries due to higher capacity of setter and hatcher, and these factors should be managed according to the factors related with breeder, egg collection and storage conditions, and incubation conditions. The aim of the current study was to assess the changes in eggshell temperatures, hatch window, hatchability and quality of broilers' chick obtained from different breeder strains in a commercial hatchery. In this study, the eggshell temperature was measured at day $18^{\text {th }}$ of incubation period to exhibit the difference between the eggs obtained from two strains in large-scale setter.

\section{Materials and Methods}

This study was performed in a commercial hatchery (HasTavuk) located in Bursa city. A total of 57 600 broiler breeder eggs were obtained from commercial Cobb 500 and Ross 308 broiler breeder parent stocks at 60-61 weeks of age flocks, respectively. The breeder flocks received a broiler breeder diet with $2750 \mathrm{kcal} \mathrm{ME} / \mathrm{kg}$ and $14.50 \% \mathrm{CP}$. The two flocks were kept under the same management conditions according to the breeding company's recommendations.

The half of breeder eggs was obtained from each strain (28 800 hatching eggs per strain, $n=192$ trays/strain, 150 eggs/tray), and each strain was randomly coded as $\mathrm{A}$ strain and $\mathrm{B}$ strain in this study. Eggs were stored at $18^{\circ} \mathrm{C}$ and $65 \% \mathrm{RH}$ for 3 days and were then warmed to room temperature $\left(21^{\circ} \mathrm{C}\right)$ for $8 \mathrm{~h}$ before setting. The eggs from each strain were randomly placed into incubator trays consisting of 150 eggs in same incubator (57 600 eggs capacity, single-stage setters, Petersime). All eggs were incubated in same incubator at $37.5^{\circ} \mathrm{C}$ and a relative humidity of $55-60 \%$ during the first 18 days of incubation. At 18 days of incubation, to evaluate the embryo temperature, the eggshell temperature was measured by contact at the equator of the egg using an infrared digital thermometer (IRT 4520, Thermoscan, Braun, Germany). The eggs (10 eggs per tray) were randomly sampled from top, middle and bottom trays with a total of 10 eggs per tray. At day 18 of incubation, eggs were weighed to determine weight loss and then randomly transferred to the three calibrated hatchers (16 800 eggs capacity, hatcher Petersime) with a temperature of $36.7^{\circ} \mathrm{C}$ and a relative humidity of $58 \%$. The egg weight loss (EWL) between 1 and 18 days of incubation was calculated according to the formula:

$$
\operatorname{EWL}(\%)=\frac{(E W B I-E W T)}{E W B I} \times 100
$$

EWBI =Egg Weight before incubation EWT= Egg weight at transfer

The ideal incubation duration was accepted as 510 hours (pulling time) in the study and the counting of the hatched chicks was performed at $486 \mathrm{~h}$ ( $24 \mathrm{~h}$ before pulling time) and at $498 \mathrm{~h}$ ( $12 \mathrm{~h}$ before of pulling time) to determine the hatch window. For each of observation 
time, the counted number of chicks was recorded than calculated as a percentage of hatched chicks by initial number of eggs.

After completing of hatching process, chicks were classified as saleable or cull chick (Tona et al., 2004). The percentage of saleable and cull chicks was expressed as a percentage of fertile eggs (Molenaar et al., 2011). Unhatched eggs were opened to macroscopically determine fertility, hatchability of total eggs and hatchability of fertile eggs. For determining the one-day old chick quality, chick body weight (given as chick hatching weight per strain), chick yield and chick body length were measured (Molenaar, 2009). The chicks were weighed at feather dryness (approximately $2 \mathrm{~h}$ post-hatch) to determine the chick hatching weight and then the chick yield was calculated as ratio between the chick hatching weight and egg setting weight (Tullett, 2009). A total of 60 chicks from each group were randomly sampled to determine cloacal temperature and chick body length. The cloacal temperatures of the chicks were also measured (to the nearest $0.01^{\circ} \mathrm{C}$ ) using a thermocouple thermometer that was inserted into the cloaca. Then the chicks from each group were measured for chick body length with $\pm 0.01 \mathrm{~cm}$ precision. Chick length was measured from the tip of the beak to the tip of the longest toe by placing the chick face down on a flat surface and straightening the left leg (Hill, 2001).

Data were subjected to analysis of t-Test: twosample as summing equal variances using Minitab (2013). Analysis for percentage data was conducted after an arcsine transformation of the data. Differences were considered significant at $P<0.05$.

\section{Result and Discussion}

The changes in eggshell temperatures of broiler eggs in top, middle and bottom trays, and the mean value of the eggshell temperature by different broiler breeder strains (Strain A and B) is given in Figure 1. The eggs obtained from Strain $A$ had a higher eggshell temperature value in top trays compared to the other eggs obtained from Strain B at 18 days of incubation $\left(101.36 \pm 0.37{ }^{\circ} \mathrm{F}\right.$ vs. $\left.100.89 \pm 0.37{ }^{\circ} \mathrm{F} ; \mathrm{P}=0.035\right)$. The eggshell temperatures of eggs placed in the middle and bottom trays had similar eggshell temperatures for both Strain A and Strain B. The mean value of eggshell temperature was found to be higher in eggs obtained from Strain $A\left(101.05 \pm 0.05^{\circ} \mathrm{F}\right)$ than the other eggs of Strain $B\left(100.98 \pm 0.05{ }^{\circ} \mathrm{F}, \mathrm{P}=0.008\right)$. These variations observed for eggshell temperatures at 18 days of age could be attributed to the genotypical differences of each breeder strain. It could be originated from different eggshell conductance, oxygen availability, metabolic rate of eggs obtained from different strains as explained by Nangsuay et al., (2016, 2017). These differences could affect nutrient metabolism, embryo development and subsequently one-day old chick quality at hatch which has potential to impact the broiler performance during post-hatch growing period (Nangsuay et al.,
2016). Current findings exhibited a significant variation for eggshell temperature between two modern broiler strains as Cobb 500 and Ross 308 which could be meaningful to optimize the incubator temperature to assure the optimum conditions for developing embryos.

The egg weight loss between 1-18 days of incubation and hatchability results of broiler eggs obtained from different strains (Strain A and Strain B) is shown on Table 1 . The egg setting weight and the egg weight loss between 1-18 days of incubation period was found to be similar for the eggs obtained from Strain $A$ and Strain B ( $P>0.05)$. A higher fertility and hatchability were observed in the broiler hatching eggs obtained from Strain A than the other eggs of Strain B $(93.7 \% \pm 4.2$ vs. $86.2 \% \pm 4.2$, and $82.2 \% \pm 3.6$ vs. $77.8 \% \pm 3.6$, respectively, $\mathrm{P}<0.01)$. The significant difference observed for fertility could be related with the management conditions at breeder farms, management conditions should be optimized according to the strain requirements during production period. Furthermore, it is well known that fertility level could be different for each strain and subsequently reflect the hatchability (Abudabos, 2010).

The hatch window of broiler eggs obtained from different breeder strains (Strain A and Strain B) is given Figure 2. The percentage of hatched chicks at $486 \mathrm{~h}$ of incubation period ( $24 \mathrm{~h}$ before pulling time) was found to be as $82.1 \%$ and $62.6 \%$ of Strain A and Strain B eggs respectively, whereas $84.9 \%$ and $67.7 \%$ of Strain $A$ and Strain B eggs at $498 \mathrm{~h}$ of incubation period ( $12 \mathrm{~h}$ before pulling time, $\mathrm{P}<0.01)$. Under commercial conditions, the spread of hatch can vary from 24 to $48 \mathrm{~h}$ (Decuypere et al., 2001; Willemsen et al., 2010). The current findings showed that the hatch window was significantly affected by broiler breeder strain, this could be related with different eggshell conductance, oxygen availability, metabolic rate of eggs obtained from different strains as explained by Nangsuay et al., $(2016,2017)$. However, in practices it is expected to complete the hatching process as soon as possible due to negative impacts of prolonged hatching phase on the development and maturation of the gastrointestinal tract, and finally chick hatching weight and broiler growth performance (Careghi et al., 2005; Mahmoud and Edens, 2012; Jacobs et al.,2017; Ozlu et al., 2018; Wang et al., 2018).

The chicks originated from Strain A hatched too early with too high percentage of hatched chicks, compared to the chicks obtained from Strain B. This fact could be related with a higher eggshell temperature as $101.05^{\circ} \mathrm{F}\left(38.36{ }^{\circ} \mathrm{C}\right)$ at 18 days of incubation, and it accelerated the hatching process. Therefore, it could be suggested that the setter temperature should be decrease about $1-2{ }^{\circ} \mathrm{F}$ to get the correct eggshell temperature in the setter. Also, other points should be checked to optimize the hatch window. For example, the pre-heating process (pre-heating temperature and duration) should be regulated by taken into consideration breeder age, strain, egg weight and age, storage conditions etc. (Pedroso et al., 2005; Ipek and 
The chick quality parameters and cloacal temperature of the chicks obtained by different broiler breeder strains (Strain A and Strain B) at hatch is given in Figure 3. Chick hatching weight was found to be in similar in chicks obtained by Strain A (45.6 g) and Strain B (45.4 g) at hatch. Chick yield was found to be higher the chicks obtained from Strain B (67.5\%), compared to the Strain A $(65.9 \% ; P<0.01)$. On the other hand, the chick body length and the cloacal temperature were similar in the chicks $(P>0.05)$. The quality of day-old chicks is vitally important for the uniform growth of chicks and the final performance of broilers (Meijerhof, 2009). For assessing of one-day old chick quality, chick hatching weight and body length was measured in the study; however, any significant differences were observed among two strains. But the relative chick weight was found to be significantly differed, this could be explained by higher eggshell temperature at 18 days of incubation observed in eggs originated from Strain A. This higher eggshell temperature could be causing an acceleration of embryo growth before hatching period and cause some developmental problems that reflected a decline in relative chick weight at hatch. Also, the higher percentage of hatched chicks at $486 \mathrm{~h}$ and $498 \mathrm{~h}$ of incubation supported this finding. Similar results are also given in a previous study performed by Sozcu et al. (2020).

Table 1. The egg weight loss between 1-18 days and hatchability results of different genotypes

\begin{tabular}{lcccc}
\hline Parameters & Genotype A & Genotype B & SEM & P Value \\
\hline Egg setting weight (g) & 69.2 & 67.3 & 2.9 & 0.054 \\
Egg weight loss (1-18 days, \%) & 10.6 & 11.0 & 0.87 & 0.436 \\
Fertility (\%) & 93.7 & 86.2 & 3.7 & $<0.01$ \\
Hatchability of total (\%) & 82.2 & 77.8 & 2.8 & 0.007 \\
Percentage of cull chicks (\%) & 0.95 & 0.83 & 0.13 & 0.145 \\
\hline
\end{tabular}

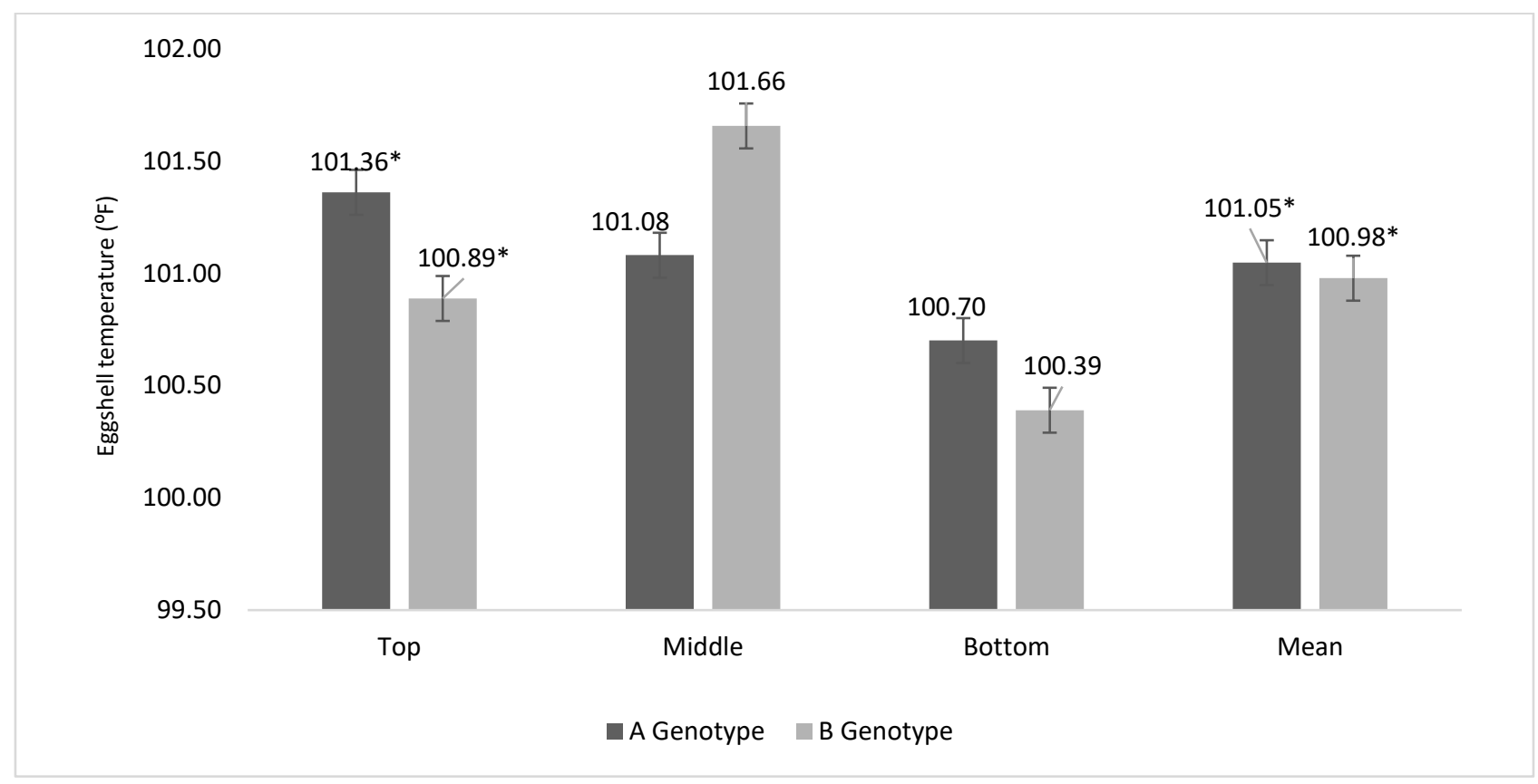

Figure 1. Changes in eggshell temperature in eggs obtained by different broiler breeder genotypes at 18 days of incubation 


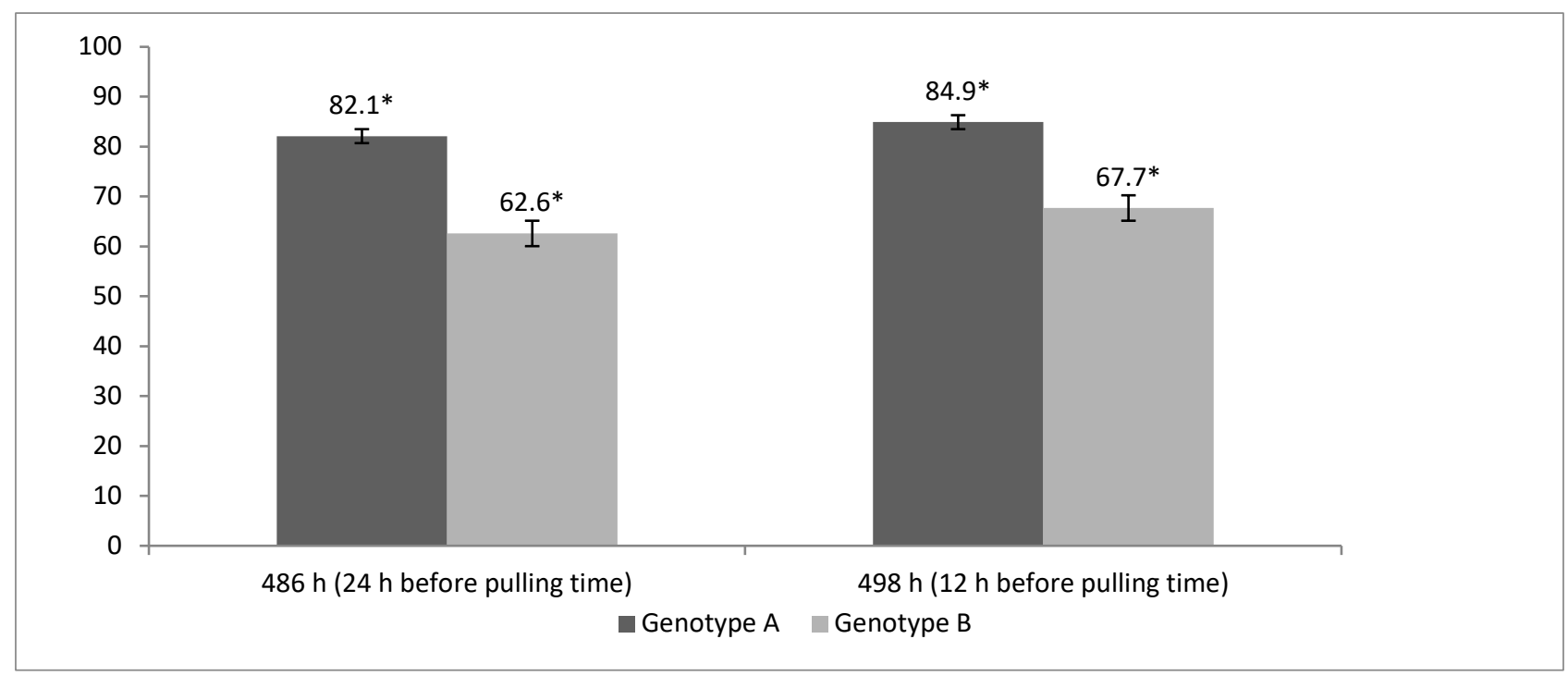

Figure 2. Hatch window eggs obtained by different genotypes

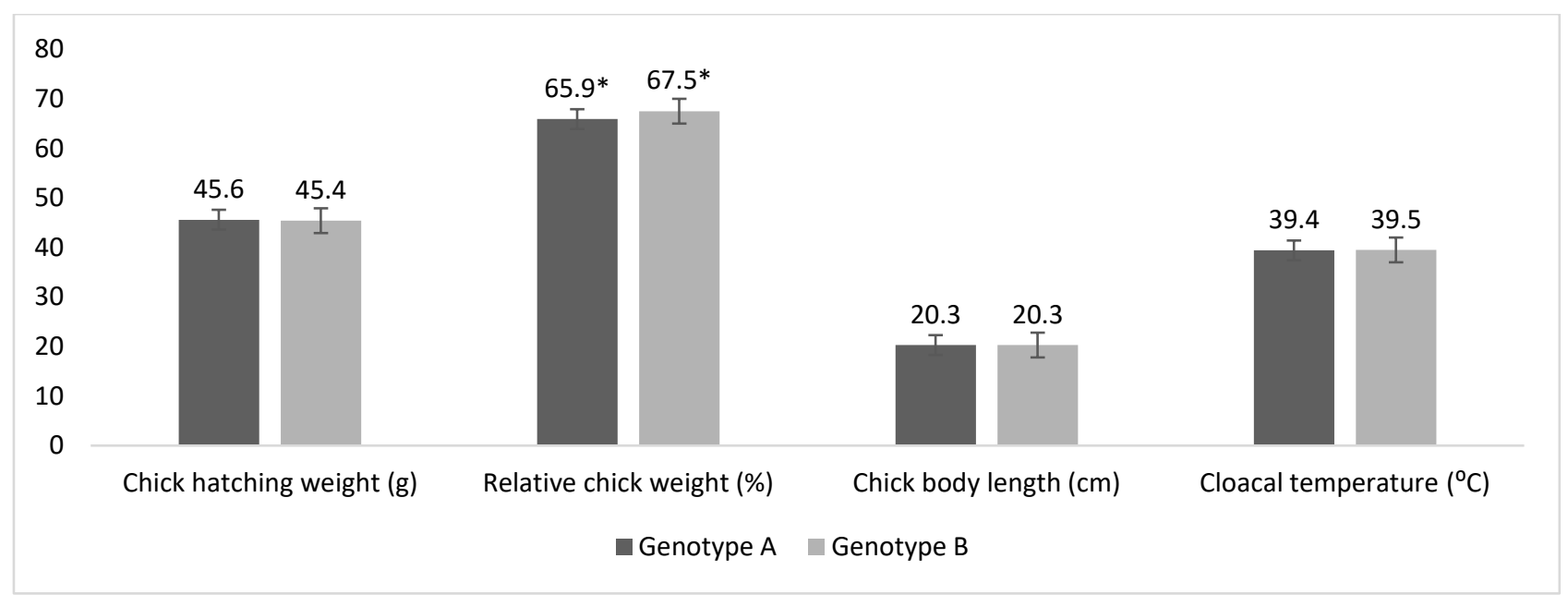

Figure 3. Chick hatching weight and chick yield in eggs obtained by different genotypes

\section{Conclusion}

As a conclusion, it could be hypothesized that the strain of breeders and eggshell temperature of eggs markedly related with other parameters for example, hatch window and possible chick quality parameters in large scale hatcheries. Results showed that higher eggshell temperature caused a speeding of hatching and undesired hatching spread of chicks. Therefore, it could be suggested that the setter temperature should be controlled during incubation period and optimized according to the breeder age, strain, egg weight and age, storage conditions etc. These findings could be instructive for commercial hatcheries about the requirements of the hatching eggs obtained from different breeder strains at particular age and contribute the optimization of eggs' management and processing.

\section{References}

Abudabos, A. 2010. The effect of broiler breeder strain and parent flock age on hatchability and fertile hatchability. International Journal of Poultry Science 9: 231-235.

Almeida, J.G., Vieira, S.L., Reis, R.N., Berres, J., Barros, R., Ferreira, A.K., Furtado, F.V.K. 2008. Hatching distrubution and embryo mortality of eggs laid by broiler breeders of different ages. Brazilian Journal of Poultry Science, 10: 89-96.

Besd-Bir. 2021. Seçilmiş Bazı Ülkelerdeki Tavuk Eti Üretimi. Available at https://besd-

bir.org/assets/uploaded/secilmis-bazi-ulkelerdekitavuk-eti-uretimi.pdf

Careghi, C., Tona, K., Onagbesan, O., Buyse, J., Decuypere, E., Bruggeman V. 2005. The effects of the spread of hatch and interaction with delayed feed access after hatch on broiler performance until seven days of age. Poultry Science 84: 1314-1320. 
Decuypere, E., Tona, K., Brugeman, V., Bramelis, F. 2001. The day-old chick: a cruical hinge between breeders and broilers. Worlds Poultry Science Journal 11: 20-23.

Dibner, J.J., Knight, C.D., Kitchell, M.L., Atwell, C.A., Downs, A.C.., Ivey, F.J. 1998. Early feeding and development of the immune system in neonatal poultry. Journal of Applied Poultry Research 7: 425-436.

Hill, D. 2001. Chick length uniformity profiles as a field measurement of chick quality. Poultry and Avian Biology Reviews 12: 188.

Ipek, A., Sahan, U., Baycan, S.C., Sozcu, A. 2014. The effects of different eggshell temperatures on embryonic development, hatchability, chick quality and first-week broiler performance. Poultry Science 93: 464-472.

Ipek, A., Sozcu A. 2015. The effects of broiler breeder age on intestinal development during hatch window, chick quality and first week broiler performance. Journal of Applied Animal Research 43(4): 402-408.

Jacobs, L., Delezie, E., Duchateau, L., Goethals, K., Ampe, B., Lambrecht E., Gellynck X., Tuyttens F.A.M. 2017. Effect of post-hatch transportation duration and parental age on broiler chicken quality, welfare and productivity. Poultry Science 95(9): 1973-1979.

Lourens, S. 2003. Residual yolk and egg weight loss during incubation under controlled eggshell temperatures. Poultry and Avian Biology Reviews 14: 209-211.

Lourens, S. 2008. Embryo temperature during incubation: practice and theory. PhD thesis, Wageningen University, The Netherlands, 1-131.

Mahmoud, K.Z., Edens, F.W. 2012. Breeder age affects small intestine development of broiler chicks with immediate or delayed access to feed. British Poultry Science53: 32-41.

Meijerhof, R. 2009. Incubation principles: what does the embryo expect from us In: Proc. of 20th Annual Australian Poultry Science Symp. Sydney, Australia pp: 106-111.

Minitab, Inc. 2013. MINITAB release 17.1.0 statistical software for windows. Minitab Inc, USA.

Molenaar, R., Hulet, R., Meijerhof, R., Maatjens, C.M., Kemp, B., Brand, H.V.D. 2011. High eggshell temperatures during incubation decrease growth performance and increase the incidence of ascites in broiler chickens. Poultry Science 90: 624-632.

Molenaar, R., Reijrink, I.A.M., Meijerhof, R., Van den Brand. H., 2010. Meeting embryonic requirement of broilers throughout incubation: a review. Brazilian Journal of Poultry Science 12: 137-148.

Molenaar, R. 2009. Evaluation of chick quality: which method do you choose? Hatchtech Incubation Technology. The Netherlands.

Nangsuay, A., Meijerhof, R., Van den Anker, I., Heetkamp, M.J.W., Kemp, B., Van den Brand, H. 2017. Effects of breeder age, strain, and eggshell temperature on nutrient metabolism of broiler embryos. Poultry Science 96: 1891-1900.

Nangsuay, A., Meijerhof, R., Van den Anker, I., Heetkamp, M.J.W., Morita, V.D.S., Kemp, B., Van den Brand, H. 2016. Effects of breeder age, broiler strain, and eggshell temperature on development and physiological status of embryos and hatchlings. Poultry Science 95: 1666-1679.
Noy, Y., Sklan, D. 1997. Posthatch development in poultry. Journal of Applied Poultry Research 6: 344-354.

Ozlu, S., Shiranjang, R., Elibol, O., Brake, J. 2018. Effect of hatching time on yolk sac percentage and broiler live performance. Brazilian Journal of Poultry Science 20 (2): 231-236.

Pedroso, A.A., Stringhini, J.H., Leandro, N.S.M., Xavier, A.S., Lima, F.G., Barbosa, C.E. 2005. Interval between removal to hatchery and lodgment of chicks with different weights provenient from young breeders. Brazilian Journal of Poultry Science 3(supl): 5.

Romanini, C.E.B., Exadaktylos, V., Tong, Q., McGonnel, I., Demmers, TGM., Bergoug, H., Etarrodossi, N., Roulston., Garain, P., Bahr, C., Berckmans, D. 2013. Monitoring the hatch time of individual chicken embryos. Poultry Science 92: 303-309.

Sozcu, A., Ipek, A. 2015. Quality assessment chicks from different hatcher temperatures with different scoring methods and prediction of broiler growth performance, Journal of Applied Animal Research 43(4): 409-416.

Sozcu, A., Ipek, A., Kahraman, M.M., Ipek, V. 2018. Effects of the biological age of broiler chickens and feed access after hatching on growth performance, serum biochemical parameters and intestinal morphology at slaughter age. European Poultry Science 82: 1-12

Sozcu, S., Ipek, A., Kahraman, M.M., Ipek, V. 2020. The effects of hatching time and feed access time on chick quality, organ development, blood parameters, and intestinal morphology in broilers. Turkish Journal of Veterinary and Animal Science 44(4): 763-773.

Tona K., Onagbesan, O., De Ketelaere, B., Decuypere, E., Bruggeman, V. 2004. Effects of age of the broiler breeders and egg storage on egg quality, hatchability, chick quality, chick weight, and chick posthatch growth to forty-two days. Journal of Applied Poultry Research 13: $10-18$.

Tullett, S. 2009. Investigating hatchery practice. Ross Tech. Scotland, United Kingdom. 2009. October.

Vieira, S.L., Pophal, S. 2000. Post-hatch nutrition of broiler chickens. Brazilian Journal of Poultry Science 2: 189-286.

Wang, J.S., Guo, T.Y., Wang, Y.X., Li, K.X., Wang, Q., Zhan, X.A. 2018. Effects of first feed intake time on growth performance, nutrient apparent metabolic rate and intestinal digestive enzyme activities in broilers. AsianAustralasian Journal of Animal Science 31 (6): 899-904.

Willemsen, H., Debonne, M., Swennen, Q., Everaert, N., Careghi, C., Han, H., Bruggeman, V., Tona, K., Decuypere, E. 2010. Delay in feed access and spread of hatch: importance of early nutrition. Worlds Poultry Science Journal 66: 177-188.

Willemsen, H., Everaert, N., Witters, A., De Dmit, L., Debonne, M., Verschuere, F., Garain, P., Berckmans, D., Decuypere, E., Bruggeman, V. 2008. Critical assessment of chick quality measurements as an indicator of posthatch performance. Poultry Science 87: 2358-2366. 